\title{
FATORES INIBIDORES DA INSTITUCIONALIZAÇÃO EM UM HOSPITAL UNIVERSITÁRIO
}

\section{INSTITUTIONALIZATION INHIBITORY FACTORS AT A UNIVERSITY HOSPITAL}

\section{FACTORES INHIBIDORES DE INSTITUCIONALIZACIÓN EN UN HOSPITAL UNIVERSITARIO}

\section{Douglas Roriz Caliman}

Mestrado em Administração pela Universidade Federal do Espírito Santo

Professor no Centro Universitário Católica Salesiana do Espírito Santo

Endereço: Av. Fernando Ferrari, n. 514, Goiabeiras. CEP: 29075-910. Vitória, ES, Brasil

Telefone: (27) 3335-2291

E-mail: douglasufes@yahoo.com.br

\section{Adna Matias Caetano}

Graduanda em Ciências Contábeis no Centro Universitário Católica Salesiana do Espírito Santo Endereço: Av. Vitória, n. 950, Forte São João, CEP: 29017-950. Vitória, ES, Brasil

Telefone: (27) 3331-8500

E-mail: adnamatias@hotmail.com

\section{Luana Brito Frassi}

Graduação em Ciências Contábeis pelo Centro Universitário Salesiana do Espírito Santo

Auxiliar Administrativo no Centro Universitário Salesiana do Espírito Santo

Endereço: Av. Vitória, n. 950, Forte São João, CEP: 29017-950. Vitória, ES, Brasil

Telefone: (27) 3331-8500

E-mail: luana_frassi@hotmail.com

\section{Sandra Mara de Castro}

Graduanda em Ciências Contábeis no Centro Universitário Católica Salesiana do Espírito Santo Endereço: Av. Vitória, n. 950, Forte São João, CEP: 29017-950. Vitória, ES, Brasil

Telefone: (27) 3331-8500

E-mail: smaracastro30@gmail.com

Artigo recebido em 21/07/2016. Revisado por pares em 12/08/2016. Reformulado em 03/11/2016. Recomendado para publicação em 25/11/2016. Publicado em 29/12/2016. Avaliado pelo Sistema double blind review. 


\section{RESUMO}

O objetivo da pesquisa foi investigar os fatores que inibem a institucionalização do orçamento como ferramenta de controle gerencial em um hospital universitário em VitóriaES. Desta forma, a compreensão do problema norteou a opção por um estudo de caso, com abordagem qualitativa e de natureza descritiva, utilizando, como procedimentos técnicos de coleta de dados, a observação não participante, entrevista semiestruturada e análise documental. O levantamento dos dados ocorreu nos meses de março e abril de 2016. Como técnica de análise de dados foi utilizada Análise de Conteúdo de Bardin (1977), desenvolvida nos meses de abril e junho de 2016. Na análise dos dados foi analisado o processo orçamentário nos planos teórico e real. Como conclusão, foram verificados 27 fatores inibidores, tais como: cultura de controle, rigidez e impessoalidade. Foi verificado, também, que o orçamento no hospital ainda não foi institucionalizado como ferramenta de controle gerencial.

Palavras chave: Orçamento; Institucionalização; Controle Gerencial.

\section{ABSTRACT}

The objective of the research was to investigate the factors that inhibit the institutionalization of the budget as a management control tool in a university hospital in Vitória-ES. Thus, understanding the problem guided the choice of a case study, with a qualitative and descriptive approach, using as technical procedures for data collection of non-participant observation, semi structured interviews and documentary analysis. The data collection took place in March and April 2016. As a data analysis was used to Bardin's content analysis technique (1977) developed in the months April and June 2016. In the data analysis, we analyzed the budget process in theoretical and real plans. In conclusion, 27 inhibitory factors were verified, such as the control cultures and rigidity and impersonal. The hospital budget has not yet been institutionalized as a management control tool.

Keywords: Budget; Institutionalization; Management control.

\section{RESUMEN}

El objetivo de esta investigación fue conocer los factores que inhiben la institucionalización del presupuesto como herramienta de control de gerencia en un hospital universitario en Vitória-ES. De esta manera, la comprensión del problema ha guiado la opción por un estudio de caso, con abordaje cualitativo y de naturaleza descriptiva, utilizando la observación no participante, entrevista semi-estructurada y análisis documental como procedimientos técnicos de colección de datos. El levantamiento de datos ha ocurrido en los meses de marzo y abril de 2016. Como técnica de análisis de datos fue utilizado el Análisis de Contenido de Bardin (1977), desarrollada en los meses de abril y junio de 2016.. En el análisis de datos fue analizado el proceso de presupuesto en los planes teórico y real. Como conclusión fueron verificados 27 factores inhibidores, tales como: cultura de control, rigidez e impersonalidad. También fue verificado que el presupuesto en el hospital todavía no fue institucionalizado como herramienta de control gerencial.

Palabras clave: Presupuesto; Institucionalización; Control Gerencial.

Revista Eletrônica de Estratégia \& Negócios, Florianópolis, v.9, n.3, set./dez. 2016. 


\section{INTRODUÇÃO}

O ambiente organizacional tem se mostrado cada vez mais volátil e imprevisível tendo, nos últimos anos, passado por significativas mudanças, o que torna a gestão mais complexa (FREZATTI et al., 2005). Em decorrência destas mudanças, as entidades sentem ainda mais a necessidade de buscar novas formas de auxílio à gestão (ANSOFF, 1991) e, consequentemente, o retorno das atividades lucrativas (SOUZA et al., 2012b).

Dentre as várias organizações existentes, a hospitalar talvez seja a mais distinta, pois une infraestrutura de instalações, equipamentos, funcionários, recursos financeiros e clientes, além de servir de auxílio à comunidade. Para uma administração eficiente, se faz necessária uma gestão competente, que coordene e controle os recursos da entidade (LINO; GONCALVES; FEITOSA, 2008). Como acontece com as empresas em geral, ferramentas de controle gerencial são cada vez mais essenciais à gestão hospitalar, pois necessitam de métodos eficientes para planejamento e execução de suas atividades, mantendo e aperfeiçoando a qualidade do serviço oferecido (SOUZA et al., 2012a).

O orçamento é a ferramenta que tem sido mais utilizada nas organizações, funcionando como instrumento de auxílio à gestão, controle e planejamento (DAVILA; WOUTERS, 2005; SANVICENTE; SANTOS, 1983). Ele integra o processo de gerenciamento, representa o plano financeiro (FREZATTI, 2007), e é um mecanismo que auxilia a empresa no estabelecimento de metas, exercendo a função de indicador, demonstrando que resultados reais podem ser medidos (VANDERBECK; NAGY, 2001).

Por ser a expressão quantitativa de um plano de ação, o orçamento caracteriza-se como um modelo de programação de atividades (PADOVEZE; TARANTO, 2009), representa os objetivos econômico-financeiros que a organização tem por objetivo atingir, e é a projeção de receitas e gastos que ela elabora para determinado período (CARNEIRO; MATIAS, 2011). É um instrumento de planejamento e controle das atividades (SANVICENTE; SANTOS, 1983), mensurador de metas (FREZATTI, 2007) e um mecanismo de autorização de gastos (ARNABOLDI; LAPSLEY; STECCOLINI, 2015).

O orçamento destina-se a orientar a administração na tarefa de controlar e dirigir a organização (SANVICENTE; SANTOS, 1983). Sua utilização em um hospital faz com que haja Revista Eletrônica de Estratégia \& Negócios, Florianópolis, v.9, n.3, set./dez. 2016. 
integração dos funcionários e dos departamentos, pois o processo orçamentário força todos os membros da administração a fazerem planos de acordo com os planos de outras unidades, fixando e quantificando precisamente os objetivos da entidade, promovendo delegação de poderes, permitindo identificar pontos de eficiência e ineficiência no desempenho dos setores, tornando possível acompanhar o progresso de cada setor, além de melhorar a utilização dos recursos disponíveis, bem como ajustá-los (com o uso racional) de acordo com as prioridades e necessidades (SANVICENTE; SANTOS, 1983).

Entretanto, apesar de toda a importância do orçamento para a gestão de uma entidade (BRYER, 2014), em muitos casos pode, ainda, ser usado de forma limitada, como mecanismo de autorização e controle dos gastos (ARNABOLDI; LAPSLEY; STECCOLINI, 2015). Quando um hospital faz o uso do orçamento como ferramenta de controle gerencial, pode-se obter como resultados: redução de perdas e retrabalhos, fomentar melhorias nos processos e auxiliar o aumento da produtividade sem perda de eficiência e qualidade (SOUZA et al., 2015). Portanto, caso seja institucionalizado, pode propiciar a avaliação de desempenho dos setores e de suas responsabilidades funcionais, através de análise de resultados, possibilitando a evolução da instituição (TOLBERT; ZUCKER, 1999; WELSCH, 1983; PADOVEZE, 2010). Pode, ainda, auxiliar na análise antecipada de políticas básicas e de capital de forma mais racional e econômica; o artefato possibilita também planejar a utilização de mão de obra e matéria-prima das instalações (SOUZA et al., 2009; PADOVEZE, 2010, WELSCH, 1983). Pode, igualmente, atuar como sistema de autorização de gastos, ser um canal de comunicação e coordenação entre os diversos níveis hierárquicos do hospital, ser um instrumento de motivação e uma fonte de informação para a tomada de decisão, sendo uma ferramenta fundamental para decisões diárias sobre os eventos econômicos de responsabilidade dos gestores (SOUZA et al., 2009; PADOVEZE, 2010, WELSCH, 1983).

Os hospitais são organizações complexas, pois enfrentam dificuldades operacionais, devido a deficiências econômico-financeiras, a formação da força de trabalho, estrutura hierárquica complexa e a especificidade dos serviços prestados tornam o gerenciamento e o controle das atividades ainda mais difíceis (SOUZA et al., 2015; SOUZA et al., 2009). São locais que agregam um conjunto variado de serviços, tais como clínicas, farmácias, lavanderias, laboratórios e outros, um grande número de especialidades e especialistas, 
diversas tecnologias e uma clientela ampla, o que demanda serviços de diferentes níveis e especialidades (PICCHIAI, 1998). Além desses fatores, a complexidade dos hospitais advém do fato que são locais onde existem constantes mudanças comportamentais dos indivíduos, a força de trabalho é singular e própria da atividade, existe uma cultura de despreocupação com custos, possuem caráter social e, em alguns casos, quando filantrópicos, possuem um aspecto de responsabilidade mais amplo e distinto do que nas organizações tradicionais (PATTIO, 2001).

Desta forma, considerando a relevância da utilização da ferramenta gerencial por uma entidade hospitalar, o estudo pode contribuir na tentativa de: a) buscar uma gestão mais eficaz, que possa contribuir fornecendo maior eficiência na utilização dos recursos, controle e medição de resultados pelos gestores de hospitais; b) compreender um pouco mais sobre as características e especificidades de uma das cinco entidades classificadas como Organizações Complexas dentro da Teoria da Complexidade, e evidenciar essas particularidades à academia.

Portanto, o estudo tem o propósito de responder a seguinte questão de pesquisa: quais os fatores que inibem a institucionalização do orçamento como ferramenta de controle gerencial em um hospital universitário de Vitória-ES? O objetivo da pesquisa é investigar os fatores que inibem a institucionalização do orçamento como ferramenta de controle gerencial em um hospital universitário federal em Vitória-ES, utilizando o modelo de Frezatti, Nascimento, Junqueira e Relvas (2011) e tendo como literatura norteadora a teoria Institucional e da Complexidade.

O estudo é relevante, pois a entidade estudada é referência em algumas áreas médicas específicas, atendendo a pacientes de todo o estado do Espírito Santo e de estados vizinhos, como Bahia, Minas Gerais e Rio de Janeiro. As constatações podem ajudar a instituição com possíveis questões a serem melhoradas em seu processo orçamentário e em seu processo decisório, contribuindo, assim, com uma possível melhoria nos serviços prestados à sociedade. Quanto à academia, a pesquisa contribui com achados ligados às especificidades de gestão de um hospital-escola e, ainda, contribui para a evolução ou aprimoramento do modelo de Frezatti et al. (2011), já que foi observada uma nova categoria de análise: complexidade organizacional.

Revista Eletrônica de Estratégia \& Negócios, Florianópolis, v.9, n.3, set./dez. 2016. 


\section{REFERENCIAL TEÓRICO}

\subsection{ORÇAMENTO}

O orçamento é o instrumento primordial de gestão em uma organização, pois envolve todos os setores da empresa (PADOVEZE, 2010). É um Sistema de Controle Gerencial que programa as ações do planejamento estratégico (FREZATTI, 2009) e estabelece um planejamento financeiro na organização para determinado período de tempo (BRAGA, 1995; FREZATTI, 2009).

O orçamento possibilita a interação entre os diversos níveis hierárquicos da organização (ALMEIDA et al., 2009) e permite, ao gestor, verificar de forma precisa a execução de suas decisões e o cumprimento dos objetivos da empresa (CASTANHEIRA et al., 2013), além de tornar possível a análise antecipada do cenário econômico, de forma a mitigar os problemas e agregar as vantagens detectadas (HORNGREN; SUNDEM; STRATTON, 2004).

O orçamento exerce várias funções na empresa, tais como: planejamento e controle de resultados (MÓL; ARAÚJO FILHO, 2008), estimula o avanço da estratégia por parte dos gestores (PADOVEZE; TARANTO, 2009), e atua como ferramenta de coordenação e organização das atividades, podendo motivar a ação dos funcionários (COVALESKI et al., 2003), e ainda ser utilizado como avaliador de desempenho (GARRISON; NOREEN, 2000).

Estudos de Luft e Shields (2003), Covaleski et al. (2003) e Hansen e Van der Stede (2004) serviram de base para que Frezatti et al. (2011) realizassem uma pesquisa em uma instituição financeira brasileira, que analisou os principais motivos para a adoção do orçamento pela entidade. Caliman (2014) e Junqueira et al. (2015) testaram o modelo em suas pesquisas.

O modelo de Frezatti et al. (2011) apresenta oito categorias relacionadas ao processo orçamentário, formado a partir das constatações de que os estudos sobre o orçamento exploravam o fenômeno de forma reducionista e não fundamentada em dados empíricos e indutivos (FREZATTI et al., 2011). Os estudos não eram abrangentes, ou seja, apenas 
descreviam especificidades das entidades que influenciavam o processo orçamentário (CALIMAN, 2014).

Caliman (2014) e Junqueira et al. (2015) testam este mesmo modelo em uma Instituição Federal de Ensino Superior (IFES) e avançam um pouco mais o modelo de Frezatti et al. (2011). Junqueira et al. (2015), por exemplo, chegam a uma variável comportamental de poder e explicam que o processo orçamentário pode ser influenciado pelo poder dos gestores.

O modelo de Frezatti et al. (2011) é caracterizado por oito categorias para análise: organização do processo de planejamento, sistema de informações, grau de participação, comunicação, constituição de reservas orçamentárias, grau da força do passado, cultura de planejamento e grau de realidade das metas.

Quadro 1 - Definições das categorias de análise

\begin{tabular}{|l|l|}
\hline CATEGORIAS & DESCRIÇÃo \\
\hline $\begin{array}{l}\text { Organização do processo de planejamento e e } \\
\text { controle }\end{array}$ & $\begin{array}{l}\text { Conjunto de recursos físicos ou não físicos } \\
\text { utilizados no processo de planejamento e } \\
\text { controle orçamentários. }\end{array}$ \\
\hline Sistema de informações & $\begin{array}{l}\text { Conjunto de recursos tecnológicos aplicados no } \\
\text { processo orçamentário. }\end{array}$ \\
\hline Grau de participação & $\begin{array}{l}\text { Envolvimento e comprometimento dos gestores } \\
\text { no processo orçamentário. }\end{array}$ \\
\hline Comunicação & $\begin{array}{l}\text { Interlocução (diálogo gerencial) entre os } \\
\text { gestores no processo orçamentário. }\end{array}$ \\
\hline Constituição de reservas orçamentárias & $\begin{array}{l}\text { Fundo orçamentário constituído para a } \\
\text { cobertura de eventuais contingências. }\end{array}$ \\
\hline Grau da força do passado & $\begin{array}{l}\text { Utilização de dados históricos (dados de } \\
\text { orçamentos anteriores) na elaboração e } \\
\text { execução do orçamento. }\end{array}$ \\
\hline Cultura de planejamento & $\begin{array}{l}\text { Instrução e conhecimento na utilização do } \\
\text { orçamento no auxílio à gestãono dia a dia. }\end{array}$ \\
\hline Grau de realidade das metas & $\begin{array}{l}\text { Veracidade entre as demandas reais e o que } \\
\text { é/foi orçado. }\end{array}$ \\
\hline
\end{tabular}

Fonte: Elaborado pelos autores (2016).

1) Organização do processo de planejamento e controle: refere-se ao conjunto de recursos físicos e tecnológicos, critérios, responsabilidades, projeções e treinamentos necessários para a iniciação do processo de planejamento (FREZATTI et al., 2011). Além destes recursos, é de grande valia para a organização investir, também, em capital humano 
(BUCKLEY; MICHIE, 1996). Quando executado corretamente, atua como facilitador do processo de administração da empresa (WELSCH, 1983).

2) Sistema de Informações: é um conjunto de recursos tecnológicos necessários para o desenvolvimento do planejamento orçamentário (FREZATTI et al., 2011). Para que seja considerado eficiente, é necessário que disponibilize informações tempestivas e que atenda as necessidades dos usuários (DAVILA; WOURTES, 2005). Quanto maior for o grau de integração dos sistemas de informação com o sistema contábil, melhor será a qualidade dos dados a serem incorporados ao orçamento (PADOVEZE; TARANTO, 2009).

3) Grau de Participação: uma das premissas para a plena execução do orçamento é o envolvimento dos gestores em sua construção (PADOVEZE; TARANTO, 2009). A participação existe para o compartilhamento das informações entre os níveis hierárquicos e para reduzir a criação de reservas orçamentárias (SHIELDS; SHIELDS, 1998). Quando bem administrado, a participação vem a ser um fator de gerenciamento de conflitos orçamentários (ETHERINGTON; TJOSVOLD).

4) Comunicação: "representa o elo que liga os elementos humanos na empresa, mas tem se demonstrado um dos problemas cruciais" (WELSCH, 1983, p. 36), visto que, quando existem falhas na comunicação, a participação dos gestores e o comprometimento organizacional ficam prejudicados (CHONG; CHONG, 2002). Quanto mais clara for a comunicação no processo orçamentário, mais facilmente os problemas serão tratados (FREZATTI, 2009).

5) Constituição de Reservas Orçamentárias: é quando ocorre intencionalmente a subestimação de receitas e/ou a superestimação de custos e despesas (DUNK; NOURI, 1998). Geralmente, a criação de reservas orçamentárias decorre da insegurança das informações fornecidas, instituição de metas irreais (FREZATTI et al., 2011), assimetria informacional, forma de condução do orçamento e apelo extremo por parte da organização em evidenciar o desempenho dos setores (DAVILA; WOUTERS, 2005).

6) Grau da Força do Passado: é comum, nas organizações, a utilização de dados históricos na elaboração do orçamento, visto que esta prática reduz tempo e gastos com 
pesquisas (FREZATTI et al., 2010), porém o seu uso traz como consequência a dificuldade na percepção de novas oportunidades (FREZATTI et al., 2011).

7) Cultura de Planejamento: é definida como o comportamento coletivo e social dos membros da organização (HEINZMANN; LAVARDA, 2011), tem por base o modelo do processo orçamentário adotado pela empresa e adquire características próprias através da ação dos gestores (PADOVEZE; TARANTO, 2009). Quando implantada de forma adequada, resulta no aumento da cooperação entre os setores, favorecendo o desempenho da organização (CHEN, 2003).

8) Grau de Realidade das Metas: para que o ambiente organizacional seja motivador, ele deve apresentar objetivos que sejam desafiadores e possíveis de se alcançar (PADOVEZE; TARANTO, 2009), pois, quanto mais irreais forem as metas estabelecidas, maiores serão as chances da criação de reservas orçamentárias (YUEN, 2004). Se o papel do orçamento não for bem compreendido pela organização, isso pode levar a mantê-lo sem alterações, mesmo se ocorrerem grandes mudanças no cenário projetado (FREZATTI et al., 2010).

\subsection{TEORIA INSTITUCIONAL}

A institucionalização trata-se de uma forma de legitimar uma organização, torná-la mais independente, sem tanta interferência do ambiente externo (TOLBERT; ZUCKER, 1999). A instituição é como se deve fazer, a organização é quem cumpre as regras definidas dentro da instituição, e a junção desses é o caminho para que ocorra a legitimação (NORTH, 1991).

A institucionalização na esfera gerencial ocorre por haver a necessidade de legitimar a organização, mas, o que se verifica é que manias são transformadas em leis dentro da instituição, para agradar o publico externo, independente da qualidade técnica do procedimento (CALIMAN, 2014; GUERREIRO et al., 2005b). Segundo Tolbert e Zucker (1999), para que o processo de institucionalização ocorra, é necessária a implantação de regras, rotinas e hábitos e, após ser aceita por todos, deixa de lado a velha história de que sempre foi assim e é por isso que eu faço, permitindo mudanças e a reestruturação da cultura da organização.

Figura 1 - Dimensão Institucional

Revista Eletrônica de Estratégia \& Negócios, Florianópolis, v.9, n.3, set./dez. 2016. 


\begin{tabular}{|l|l|l|}
\hline \multicolumn{1}{|c|}{ DIMENSÃO INSTITUCIONAL } & \\
\hline \multicolumn{1}{|c|}{ Hábitos } & \multicolumn{1}{|c|}{ Instituições } \\
\hline
\end{tabular}

Fonte: Guerreiro, Pereira e Frezatti (2008, p. 48).

O orçamento, que é uma ferramenta da contabilidade gerencial, pode ser institucionalizado e, assim, permitir que a entidade evolua e se firme na cultura organizacional, o que permitirá melhor utilização desta ferramenta e maior satisfação dos usuários (CALIMAN, 2014; ZAN, 2006; TOLBERT; ZUCKER, 1999). O processo orçamentário, caso institucionalizado, pode se tornar inquestionável, já que minimiza as falhas e o risco de dissolução da empresa, pois as decisões serão tomadas e seus resultados alcançados com base em doutrinas amplamente aceitas e seguidas, que presam pela sobrevivência da organização (MEYER; ROWAN, 1977; CALIMAN, 2014; BURNS; SCAPENS, 2000).

\subsubsection{Fases de Institucionalização}

Tolbert e Zucker (1999) ponderam que o processo de institucionalização passa por três estágios: habitualização, objetivação e sedimentação, e Aguiar et al. (2005) destacam, ainda, que é este processo que vai definir se a reestruturação organizacional vai ser bem sucedida ou não.

Figura 2 - Processos Inerentes a Institucionalização 


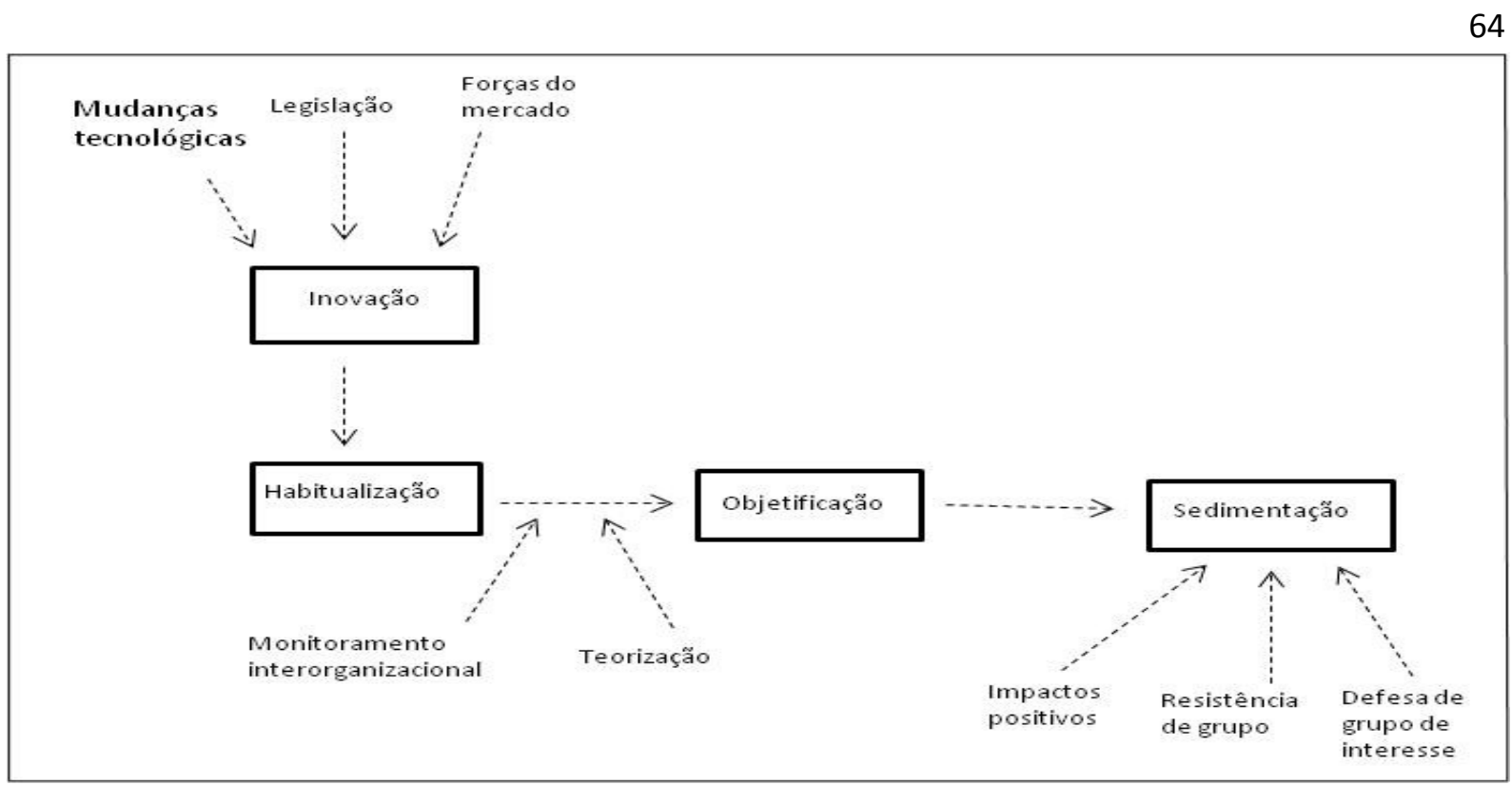

Fonte: Tolbert e Zucker, p. 205 (2006).

Inicia-se a institucionalização com a habitualização, que é a implantação de novas políticas para solução de problemas e, nesse estágio, há um elevado nível de fracasso (OYADOMARI et al., 2008), que faz com que a empresa busque maneiras de lidar com a situação da melhor forma. Uma delas é a utilização do mimetismo, adotando o mesmo procedimento de outra empresa, tentando buscar o melhor resultado (TOLBERT; ZUCKER, 1999).

Após a inicialização do processo de institucionalização, tem início a fase da objetivação, que é a transição da pré-institucionalização (habitualização) até a institucionalização total (sedimentação), onde são difundidas as normas da nova estruturação a todos os membros da organização para explicar que a institucionalização será implantada para resolução de problemas (PASSOLONGO; ICHIKAWA; REIS, 2004). Este processo, para que venha a obter resultado positivo, segundo Tolbert e Zucker (1999), é necessária a aceitação e colaboração dos membros da empresa e, também, que seja realizado um monitoramento (PASSOLONGO; ICHIKAWA; REIS, 2004). Esta etapa envolve o isomorfismo normativo (PASSOLONGO; ICHIKAWA; REIS, 2004).

A institucionalização, segundo Tolbert e Zucker (1999), finaliza com a sedimentação, que é quando a institucionalização é aceita e impetrada na operacionalização da instituição por toda sua continuidade histórica. Passolongo, Ichikawa e Reis (2004) destacam que, nesta etapa, o isomorfismo coercitivo está presente por ter base legal. A organização só estará 
sedimentada se a institucionalização permanecer durante várias gerações (TOLBERT; ZUCKER, 1999).

\subsubsection{A influência do isomorfismo na institucionalização}

O isomorfismo caracteriza-se pela necessidade que as empresas têm de realizar praticas compatíveis com outras de um mesmo segmento, o que ocasiona uma semelhança entre elas (PASSOLONGO; ICHIKAWA; REIS, 2004). Dessa forma, há três tipos de isomorfismo: Coercitivo, Mimético e Normativo (DIMAGGIO; POWELL, 1983).

No isomorfismo coercitivo, a gestão sede a pressões formais advindas de leis ou da política de modo informal. Um exemplo é quando uma filial é forçada a implantar o mesmo tipo de sistemática da central (OYADOMARI et al., 2008). Dimaggio e Powell (1983) corroboram afirmando que a influência sofrida pela pressão do governo causa uma mudança na organização; assim, passam a pensar na institucionalização de acordo com as leis e normas do Estado.

O Isomorfismo mimético apresenta padrões criados em momentos de incertezas do mercado e, levados pela dúvida na tomada de decisão, julgam necessário e mais viável para a empresa imitar ou copiar a decisão que foi tomada por outras do mesmo ramo de atividade, visando, assim, a diminuir custos com a busca por outras soluções viáveis (OYADOMARI et al., 2008). Para Dimaggio e Powell (1983), a organização busca uma maneira eficaz de minimizar as incertezas, copiando outras organizações em busca do melhor resultado.

Dimaggio e Powell (1983) associam o isomorfismo normativo à profissionalização e às necessidades dos membros de uma mesma área de atuação em definirem quais condições e métodos utilizarão para o seu trabalho. Oyadomari et al. (2008) corroboram com Dimaggio e Powell (1983), e acrescentam que o isomorfismo normativo tem três passos para a uniformização: o conhecimento transmitido através dos professores de um conteúdo padronizado; relacionamento com pessoas da mesma área e que também aprenderam o mesmo conteúdo; e a seleção de profissionais com as mesmas características para a atuação.

\subsection{TEORIA DA COMPLEXIDADE}

Revista Eletrônica de Estratégia \& Negócios, Florianópolis, v.9, n.3, set./dez. 2016. 
Compreender as especificidades de uma organização complexa, na esfera gerencial, é de extrema importância para ajudar a entender os fenômenos ligados ao processo decisório dessas organizações.

A Teoria da Complexidade surgiu por volta dos anos 60, com a junção de várias outras, como a do caos, fractais, das catástrofes e da lógica fuzzy (GERSHENSON; HEYLIGHEN, 2005; TORRES, 2005). Para compreender essa teoria é importante entender, primeiramente, o conceito de ordem e desordem (ESTRADA, 2009).

A ordem está ligada ao equilíbrio, à organização e à interação de elementos organizacionais (MORIN, 2005); e a desordem é o seu oposto, ou seja, são falhas, erros, ruídos, e irregularidades que estão geralmente ligadas ao caos e ao imprevisível (ESTRADA, 2009; MORIN, 2005). Nas entidades complexas, tais como hospitais, museus, universidades, penitenciárias e igrejas, a ordem é conseguida através da desordem, que é a interação de vários elementos (MORIN, 2005). Nessas organizações é importante compreender o sistema como um todo, ao invés de analisar as partes individualmente (MORIN, 2005).

Os hospitais são ótimos exemplos de organizações complexas, devido a fatores como o uso de tecnologias complexas, burocracias, autonomia técnica, pluralidade de profissionais e objetivos difusos (MEYER JR., 2007; MINTZBERG, 2007; PASCUCCI; MEYER JR., 2011). Podem, ainda, ser entidades com diversas características, tais como: a imprevisibilidade e a não linearidade das atividades (ETZIONE, 1964; MEYER JR., 2007), organizações frouxamente articuladas (WEICK, 1976), auto-organização (MORIN, 2005), processo decisório informal, burocrático e contrário às abordagens racionais (MEYER JR., 2007), redes de feedback (interações) (STACEY, 1996), e influências políticas nos processos de gestão (ALDRIDGE; RILEY, 1977).

Uma maneira que as organizações têm de se adaptarem a este ambiente é a implantação de um Sistema Adaptativo Complexo (SAC), que se diferencie dos demais sistemas por ser capaz de evoluir e se adaptar a cada situação já vivenciada (HOLLAND, 1996). É um sistema autônomo, que é capaz de aprender com os erros e falhas que, por conseguinte, consegue corrigir e melhorar seus processos, evitando que esse mesmo erro ou falha volte a ocorrer (AGOSTINHO, 2003). Porém, para que sua implantação ocorra de Revista Eletrônica de Estratégia \& Negócios, Florianópolis, v.9, n.3, set./dez. 2016. 
maneira correta e clara, os indivíduos devem ser capazes de definir os objetivos da organização e de mantê-los alinhados (PASCUCCl; MEYER JR., 2011).

\subsection{ESTUDOS ANTERIORES}

O tema vem sendo bastante estudado nos últimos anos, por conceituados pesquisadores, tanto no Brasil como no exterior. A teoria contribui para a ciência da contabilidade, pois ajuda a explicar de que forma as ferramentas gerenciais são utilizadas nas entidades e o impacto dessa utilização no sistema decisório como um todo, e para tentar entender por que a contabilidade gerencial não tem se modificado, mesmo com a mudança do contexto e da realidade social (GUERREIRO et al., 2005a; MACHADO-DA-SILVA; FONSECA; CRUBELLATE, 2010; CALIMAN, 2014).

Ao estudar as características do processo orçamentário em cooperativas de crédito no estado de Minas Gerais, Sarkis (2013) concluiu que as mesmas não empregavam o orçamento na forma prevista pela literatura, executando o processo orçamentário de forma precária, o que limitava os resultados e benefícios esperados do orçamento, ou seja, o que era definido na teoria, não era posto em prática. Caliman (2014) analisou, em uma Instituição Federal de Ensino Superior do Espírito Santo, as variáveis que inibiam a institucionalização do orçamento e, ao final do estudo, identificou dezesseis fatores inibidores do orçamento, além de concluir que o mesmo era parcialmente institucionalizado na organização.

Livovschi (2013) estudou os possíveis fatores socioculturais que agiam como facilitadores da institucionalização do orçamento em um grupo de médias e grandes empresas, e verificou que os valores sociais, cronogramas definidos e a clareza das diretrizes foram fundamentais em promover a institucionalização do orçamento. Junqueira et al. (2015) utilizaram a análise do orçamento proposto por Frezatti et al. (2011) em uma Instituição Federal de Ensino Superior localizada no sudeste do Brasil, e concluíram que o orçamento não era utilizado como artefato gerencial, e que a forma de gestão adotada pela IFES inibia a participação dos gestores, sendo o processo orçamentário influenciado por questões relacionadas a relações políticas e de poder.

\section{PROCEDIMENTOS METODOLÓGICOS}

Revista Eletrônica de Estratégia \& Negócios, Florianópolis, v.9, n.3, set./dez. 2016. 
Para aumentar a fidedignidade foi desenvolvido um protocolo de estudo de caso contendo os procedimentos e regras para o desenvolvimento da pesquisa (Yin, 1989). O protocolo destaca: a) visão geral da pesquisa; b) questão e objetivo de pesquisa; c) procedimentos de campo (locais, fontes de informação e formulários para registro de dados), método de pesquisa, aplicação e uso dos instrumentos de captação de dados; d) teorias de base do estudo; e e) guia de relatório do estudo de caso (YIN, 1989).

O presente estudo é de natureza descritiva (GIL, 2009). A entidade estudada foi um Hospital Universitário situado na cidade de Vitória-ES. Foram utilizadas três fontes de coleta de dados: entrevista, observação não participante e análise documental. As entrevistas foram realizadas durante os meses de março e abril de 2016. As entrevistas e a observação participante tinham como objetivo identificar as práticas gerenciais institucionalizadas, o grau de conhecimento, o envolvimento dos agentes da organização, assim como a participação e a comunicação no plano real. Com a análise documental mostrou-se de que forma o processo orçamentário se dava no plano teórico. Em um segundo momento, com a análise de conteúdo (BARDIN, 1977), analisaram-se os fatores que inibiam a institucionalização do orçamento como artefato de controle gerencial.

Foram entrevistados dois funcionários administrativos diretamente envolvidos na elaboração, acompanhamento e gerenciamento do orçamento. Os entrevistados foram selecionados intencionalmente, considerando a preferência por agentes envolvidos diretamente na elaboração, execução e controle orçamentário dos hospitais. Com o objetivo de testar o questionário, foi aplicado um pré-teste a um respondente, em um contexto similar ao analisado, para ajustes, retificações e aprimoramentos do mesmo. As entrevistas duraram aproximadamente 3 horas cada uma. No entanto, os entrevistados solicitaram que as mesmas não fossem gravadas.

Os entrevistados possuíam, em média, oito anos na Instituição, e idade média de 35 anos. Quanto à formação, ambos eram Contadores, sendo todos pós-graduados, um deles possuindo mestrado profissional na área de gestão pública. A participação foi voluntária e natural, juntamente com o anonimato, que foi a variável importante para dar maior confiabilidade nas informações obtidas. 
A análise documental foi desenvolvida com o acesso aos seguintes documentos: (a) o Plano Estratégico ou Plano de Desenvolvimento Institucional (PDI), (b) o orçamento, (c) documentos relacionados com o processo orçamentário do hospital, e (d) acesso ao portal de informações da instituição. Foi importante ajudar a captar informações no plano teórico para, posteriormente, confrontar com as informações da observação participante e a entrevista.

Quanto à observação não participante, um dos pesquisadores não é funcionário do hospital, mas é responsável por analisar alguns procedimentos contábeis e de gestão da entidade. Desta forma, consegue-se visualizar as tomadas de decisão e a execução orçamentária, mas não participa influenciando o processo orçamentário. Com a observação não participante, foi possível observar as disparidades entre o que é praticado no dia a dia e o que é discutido no plano teórico no hospital.

As entrevistas foram analisadas por meio de técnicas de análise de conteúdo (Bardin, 1977), tendo como base o conjunto de categorias e fatores propostos no modelo de Frezatti et al. (2011).

Após a descrição de todo o método da pesquisa, são apresentadas as categorias de análise que compõem o estudo. A definição constitutiva é a definição conceitual, e definição operacional é a forma como tais conceitos fora operacionalizados no estudo (RICHARDSON, 1999).

Quadro 2 - Definições das categorias de análise

\begin{tabular}{|l|l|l|}
\hline CATEGORIAS DE ANÁLISE & $\begin{array}{l}\text { DEFINIÇÃO } \\
\text { CONSTITUTIVA }\end{array}$ & $\begin{array}{l}\text { DEFINIÇÃO } \\
\text { OPERACIONAL }\end{array}$ \\
\hline \multirow{5}{*}{$\begin{array}{l}\text { Complexidade organizacional } \\
\text { contribuir para um novo } \\
\text { entendimento de problemas } \\
\text { organizacionais (LISSACK; } \\
\text { LETICHE, 2002). }\end{array}$} & $\begin{array}{l}\text { lontextos de aprendizagem, } \\
\text { autonomia, organização, } \\
\text { previsibilidade, padronização, } \\
\text { retorno da informação e } \\
\text { relações interpessoais. }\end{array}$ \\
\hline $\begin{array}{l}\text { Estrutura do processo } \\
\text { orçamentário }\end{array}$ & $\begin{array}{l}\text { Estrutura que compõe o o } \\
\text { planejamento orçamentário } \\
\text { (processo que implementa os } \\
\text { planos do Planejamento } \\
\text { Estratégico no curto prazo) } \\
\text { (FREZATTI et al., 2011). }\end{array}$ & $\begin{array}{l}\text { Conjunto de recursos físicos e } \\
\text { tecnológicos, } \\
\text { critérios, responsabilidades, } \\
\text { projeções e treinamentos do } \\
\text { Hospital. }\end{array}$ \\
\hline
\end{tabular}


FATORES INIBIDORES DA INSTITUCIONALIZAÇÃO EM UM HOSPITAL UNIVERSITÁRIO

Sandra Mara de Castro - Luana Brito Frassi - Adna Matias Caetano - Douglas Roriz Caliman

\begin{tabular}{|c|c|c|}
\hline Sistema de informações & $\begin{array}{l}\text { Conjunto de recursos } \\
\text { tecnológicos } \\
\text { necessários para } \\
\text { desenvolvimento do processo } \\
\text { orçamentário (FREZATTI et al., } \\
\text { 2011). }\end{array}$ & $\begin{array}{l}\text { Sistema de contabilidade e de } \\
\text { administração financeira } \\
\text { utilizados no processo } \\
\text { orçamentário do Hospital. }\end{array}$ \\
\hline Grau de participação & $\begin{array}{l}\text { Envolvimento dos gestores no } \\
\text { processor orçamentário } \\
\text { (FREZATTI et al., 2011). }\end{array}$ & $\begin{array}{l}\text { Envolvimento dos gestores no } \\
\text { processo orçamentário do } \\
\text { Hospital. }\end{array}$ \\
\hline Comunicação & $\begin{array}{l}\text { Elo dos elementos humanos no } \\
\text { processor orçamentário } \\
\text { (FREZATTI et al., 2011). }\end{array}$ & $\begin{array}{l}\text { Forma de comunicação } \\
\text { gerencial } \\
\text { utilizada no processo } \\
\text { orçamentário } \\
\text { pelos gestores do Hospital. }\end{array}$ \\
\hline $\begin{array}{l}\text { Constituição de reservas } \\
\text { orçamentárias }\end{array}$ & $\begin{array}{llr}\text { Reservas } & \text { constituídas } \\
\text { intencionalmente } & \text { pelos } \\
\text { gestores no } & \text { processo } \\
\text { orçamentário } & \text { (FREZATTI et al., } \\
\text { 2011). } & & \end{array}$ & $\begin{array}{l}\text { Reservas orçamentárias } \\
\text { constituídas } \\
\text { para eventuais manobras de } \\
\text { gestão (dentro da legalidade). }\end{array}$ \\
\hline Grau da força do passado & $\begin{array}{l}\text { Adoção de dados históricos na } \\
\text { elaboração do orçamento } \\
\text { (FREZATTI et al., 2011). }\end{array}$ & $\begin{array}{l}\text { Utilização de estimativas } \\
\text { anteriores } \\
\text { para o desenvolvimento do } \\
\text { orçamento do Hospital. }\end{array}$ \\
\hline Cultura de planejamento & $\begin{array}{l}\text { lomportamento coletivo e } \\
\text { social dos membros da } \\
\text { organização na utilização do } \\
\text { orçamento (FREZATTl et al., } \\
\text { 2011). }\end{array}$ & $\begin{array}{l}\text { Comportamento coletivo e } \\
\text { social dos gestores do hospital } \\
\text { na utilização do orçamento } \\
\text { como ferramenta de controle. }\end{array}$ \\
\hline Grau de realidade das metas & $\begin{array}{l}\text { Realidade das metas } \\
\text { orçamentárias inseridas pelos } \\
\text { gestores (FREZATTI et al., } \\
\text { 2011). }\end{array}$ & $\begin{array}{llr}\text { Percepção } & \text { dos } & \text { gestores } \\
\text { quanto } & \text { às } & \text { metas } \\
\text { orçamentárias } & \text { inseridas } & \text { pela } \\
\text { administração } & \text { central do } \\
\text { Hospital. } & & \\
\end{array}$ \\
\hline
\end{tabular}

Fonte: Elaborado pelos autores (2016).

A análise de dados foi desenvolvida pela técnica de Análise de Conteúdo de Bardin (1977), e foi dividida em três etapas: 1) Pré-análise: foram definidos o corpus preliminar da pesquisa, a unidade de análise (palavra) e as categorias analíticas e fatores preliminares de análise (conforme estudo de Frezatti et al., 2011); 2) Exploração do material (análise): foi definido o corpus da pesquisa, com as categorias e fatores de análise, determinando a composição das categorias (através da classificação análoga de elementos), definindo as regras de análise (polos positivo e negativo) e escolhida e aplicada a grade de análise mista; 3) Tratamento de resultados: utilizado o método de emparelhamento de resultados com o uso da teorias de orçamento, institucional e complexa. 


\section{ANÁLISE DOS RESULTADOS}

Nos quadros a seguir, a coluna Como é (plano real) reflete os dados coletados nas entrevistas e observação não participante, e a coluna Como deveria ser (plano teórico) mostra o que a literatura destaca sobre determinada categoria/fator. Cabe salientar, ainda, que o foco da pesquisa está nos fatores inibidores. Para auxiliar a análise e a visualização do que a nomenclatura frisa e o que é praticado, foi inserida nos quadros, juntamente com a coluna Inibe, a coluna Estimula. Desta forma, podem-se comparar os dados obtidos na pesquisa com os conceitos da literatura de orçamento e controle gerencial.

Nesta etapa utilizaram-se as categorias e fatores de análise do estudo de Frezatti et al. (2011). Entretanto, a categoria complexidade organizacional não consta no trabalho de Frezatti et al. (2011). Surgiu através da observação não participante, embasada no trabalho de Meyer e Pascuci (2013). Desta forma, assim como os trabalhos de Junqueira et. al. (2015) e de Caliman (2014), que conseguiram evoluir o modelo de Frezatti et al. (2011), esta pesquisa contribui com mais sete fatores de análise, por se tratar de um hospital, que é uma organização classificada como Organização Complexa.

Quadro 3 - Categoria Organização Complexa

\begin{tabular}{|c|c|c|c|c|c|c|}
\hline \multirow[t]{3}{*}{ Categoria } & \multirow[t]{3}{*}{ Fatores } & \multirow[t]{3}{*}{ Descrição } & \multicolumn{4}{|c|}{$\begin{array}{l}\text { Impacto sobre } \\
\text { Institucionalização }\end{array}$} \\
\hline & & & \multicolumn{2}{|c|}{ Como é } & \multicolumn{2}{|c|}{$\begin{array}{l}\text { Como deveria } \\
\text { ser }\end{array}$} \\
\hline & & & Inibe & Estimula & Inibe & Estimula \\
\hline \multirow[t]{5}{*}{$\begin{array}{l}\text { Complexidade } \\
\text { Organizacional }\end{array}$} & Aprendizado & $\begin{array}{l}\text { Processo de aprendizagem } \\
\text { como resultado de } \\
\text { atividades não lineares. }\end{array}$ & & $x$ & & $X$ \\
\hline & Autonomia & $\begin{array}{l}\text { Independência na } \\
\text { execução dos processos e } \\
\text { atividades. }\end{array}$ & $x$ & & $x$ & \\
\hline & $\begin{array}{l}\text { Auto- } \\
\text { organização }\end{array}$ & $\begin{array}{l}\text { Ajuste espontâneo do } \\
\text { sistema (reorganização). }\end{array}$ & & $x$ & & $x$ \\
\hline & Imprevisibilidade & $\begin{array}{l}\text { Dificuldade de previsão de } \\
\text { mudanças internas e } \\
\text { externas para o sistema } \\
\text { como um todo. }\end{array}$ & $x$ & & $x$ & \\
\hline & Não linearidade & $\begin{array}{l}\text { Processo ou atividade não } \\
\text { padronizado. }\end{array}$ & $x$ & & $x$ & \\
\hline
\end{tabular}

Revista Eletrônica de Estratégia \& Negócios, Florianópolis, v.9, n.3, set./dez. 2016. 


\begin{tabular}{|l|l|l|l|l|l|l|}
\hline & Feedback & $\begin{array}{l}\text { Retroalimentação de } \\
\text { informações no sistema } \\
\text { devido a interações com o } \\
\text { ambiente. }\end{array}$ & X & & X \\
\cline { 2 - 7 } & $\begin{array}{l}\text { Relações } \\
\text { políticas }\end{array}$ & $\begin{array}{l}\text { Sistema caracterizado pela } \\
\text { informalidade, objetivos } \\
\text { limitados e ilegítimos. }\end{array}$ & $\mathrm{X}$ & & $\mathrm{X}$ & \\
\hline
\end{tabular}

Fonte: Elaborado pelos autores (2016).

Dentre os fatores inibidores da categoria, o fator que mais se destacou foi Relações Políticas, pois as relações interpessoais aceleram o andamento de uma compra ou qualquer outro tipo de transação que afete o orçamento, corroborando com o estudo de Junqueira et al. (2015). A famosa conversa pessoal com o processo embaixo do braço é muito comum, e este tipo de contato gera mudanças no andamento da execução orçamentária. Um fator que contribui para as relações políticas é a pluralidade de profissionais, ou seja, há um tipo de coalizão entre grupos profissionais que faz este tipo de relação ser perceptível dentro da organização estudada, e influencia o processo orçamentário com o compartilhamento de ideias e práticas, convergindo com o estudo de Reis et al. (2014).

Quadro 4-Categoria Organização e Estrutura do Processo Orçamentário

\begin{tabular}{|c|c|c|c|c|c|c|}
\hline \multirow{3}{*}{ Categoria } & \multirow{3}{*}{ Fatores } & \multirow{3}{*}{ Descrição } & \multicolumn{4}{|c|}{$\begin{array}{l}\text { Impacto sobre } \\
\text { Institucionalização }\end{array}$} \\
\hline & & & \multicolumn{2}{|c|}{ Como é } & \multicolumn{2}{|c|}{$\begin{array}{l}\text { Como deveria } \\
\text { ser }\end{array}$} \\
\hline & & & Inibe & Estimula & Inibe & Estimula \\
\hline \multirow{5}{*}{$\begin{array}{l}\text { Estrutura do } \\
\text { Processo } \\
\text { Orçamentári } \\
\text { o }\end{array}$} & \multirow{3}{*}{$\begin{array}{l}\text { Configuração } \\
\text { e gestão do } \\
\text { processo } \\
\text { orçamentário }\end{array}$} & $\begin{array}{ll}\text { Recursos tecnológicos } \\
\text { disponibilizados aos gestores. }\end{array}$ & & $x$ & & $x$ \\
\hline & & $\begin{array}{l}\text { Estruturação e divulgação da } \\
\text { agenda do processo } \\
\text { orçamentário (planejamento, } \\
\text { execução e controle). }\end{array}$ & $x$ & & & $X$ \\
\hline & & $\begin{array}{l}\text { Gerenciamento do processo } \\
\text { orçamentário (planejamento, } \\
\text { execução e controle). }\end{array}$ & $x$ & & & $X$ \\
\hline & $\begin{array}{l}\text { Definição de } \\
\text { critérios de } \\
\text { planejamento }\end{array}$ & $\begin{array}{l}\text { Seleção de parâmetros para } \\
\text { comparação do orçado e } \\
\text { realizado. }\end{array}$ & $x$ & & & $X$ \\
\hline & Feedback & $\begin{array}{l}\text { Sistemática eficaz de controle } \\
\text { do processo de planejamento } \\
\text { frente aos resultados } \\
\text { esperados. }\end{array}$ & $x$ & & & $x$ \\
\hline
\end{tabular}

Revista Eletrônica de Estratégia \& Negócios, Florianópolis, v.9, n.3, set./dez. 2016. 


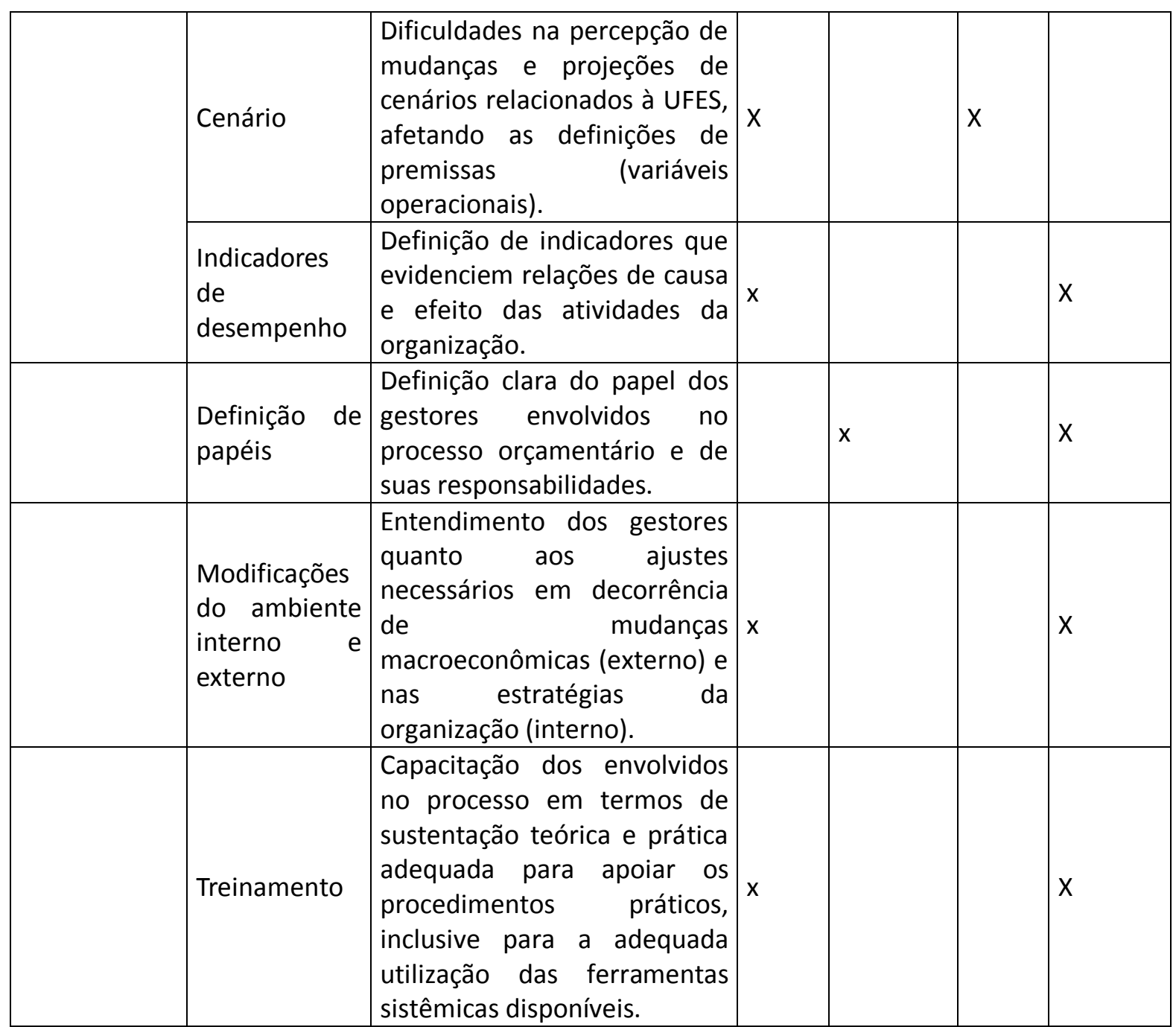

Fonte: Elaborado pelos autores (2016).

As deficiências da estrutura contribuem bastante com a inibição da utilização do orçamento como ferramenta de controle gerencial, visto que os servidores não recebem nenhum tipo de treinamento sobre orçamento. Os servidores que recebem cargos de gestão não são treinados, não sabem ler demonstrações e relatórios orçamentários, não conseguem fazer suas análises e assim, consequentemente, não dão a devida importância à ferramenta. No geral, a estrutura não está preparada, ainda, para compreender o orçamento como ferramenta gerencial. Mesmo o hospital passando por mudanças administrativas nos últimos cinco anos, não foi suficiente para este entendimento. Não há um planejamento claro, as estruturas ainda são arcaicas, não há indicadores de desempenho fidedignos e, também há a dificuldade de enxergar o cenário externo e sua influência na ferramenta e, por conseguinte, na tomada de decisão. Estas características convergem com o estudo de Caliman (2014). 


\begin{tabular}{|c|c|c|c|c|c|c|}
\hline \multirow{3}{*}{ Categoria } & \multirow{3}{*}{ Fatores } & \multirow{3}{*}{ Descrição } & \multicolumn{4}{|c|}{$\begin{array}{l}\text { Impacto sobre a } \\
\text { Institucionalização }\end{array}$} \\
\hline & & & \multicolumn{2}{|c|}{ Como é } & \multicolumn{2}{|c|}{$\begin{array}{l}\text { Como deveria } \\
\text { ser }\end{array}$} \\
\hline & & & Inibe & Estimula & Inibe & $\begin{array}{l}\text { Estimul } \\
\text { a }\end{array}$ \\
\hline \multirow{4}{*}{$\begin{array}{l}\text { Sistemas } \\
\text { de } \\
\text { Informaçã } \\
\text { o }\end{array}$} & $\begin{array}{l}\text { Disponibilida } \\
\text { de de } \\
\text { informação }\end{array}$ & $\begin{array}{l}\text { Geração e fornecimento de } \\
\text { informações adequadas às } \\
\text { demandas dos centros de } \\
\text { ensino e pró-reitorias. }\end{array}$ & $x$ & & & $x$ \\
\hline & $\begin{array}{l}\text { Ferramentas } \\
\text { de sistemas }\end{array}$ & $\begin{array}{l}\text { Hardware adequado às } \\
\text { necessidades e Softwares } \\
\text { integrados, incluindo } \\
\text { ferramentas para extração } \\
\text { de dados, projeções, } \\
\text { simulações (quantitativas e } \\
\text { financeiras) e geração de } \\
\text { relatórios. }\end{array}$ & $x$ & & & $x$ \\
\hline & $\begin{array}{l}\text { Tempestivida } \\
\text { de da } \\
\text { informação }\end{array}$ & \begin{tabular}{|lrr}
$\begin{array}{l}\text { Fornecimento } \\
\text { informações }\end{array}$ & de das \\
oportuna & (momento \\
adequado). & &
\end{tabular} & & $x$ & & $x$ \\
\hline & $\begin{array}{l}\text { Qualidade da } \\
\text { informação }\end{array}$ & $\begin{array}{l}\text { Informações fidedignas e } \\
\text { confiáveis. }\end{array}$ & & $x$ & & $x$ \\
\hline
\end{tabular}

Fonte: Elaborado pelos autores (2016).

Foi observado que, mesmo a instituição possuindo um sistema de administração financeira específico, ela não consegue gerenciar as informações de forma satisfatória, visto que a informação existe, mas não são todos os gestores que possuem acesso e não há relatórios gerenciais específicos evidenciados no sistema. O sistema é fechado a alguns profissionais, devido à complexidade de sua operacionalização e à própria dificuldade na leitura e entendimento das informações para quem não é da área financeira e não é integrado a diversas áreas, convergindo com o estudo de Frezatti et al. (2011).

Quadro 6 - Categoria Participação No Processo Orçamentário

\begin{tabular}{|c|c|c|c|c|c|c|}
\hline \multirow{3}{*}{ Categoria } & \multirow{3}{*}{ Fatores } & \multirow{3}{*}{ Descrição } & \multicolumn{4}{|c|}{\begin{tabular}{|l|} 
Impacto sobre a \\
Institucionalização
\end{tabular}} \\
\hline & & & \multicolumn{2}{|c|}{ Como é } & \multicolumn{2}{|c|}{$\begin{array}{l}\text { Como deveria } \\
\text { ser }\end{array}$} \\
\hline & & & Inibe & $\begin{array}{l}\text { Estim } \\
\text { ula }\end{array}$ & $\begin{array}{l}\text { Inib } \\
\mathrm{e}\end{array}$ & $\begin{array}{l}\text { Estimul } \\
\text { a }\end{array}$ \\
\hline $\begin{array}{l}\text { Participação } \\
\text { no Processo }\end{array}$ & Top down & $\begin{array}{l}\text { Imposição de metas } \\
\text { orçamentárias sem }\end{array}$ & $x$ & & $x$ & \\
\hline
\end{tabular}

Revista Eletrônica de Estratégia \& Negócios, Florianópolis, v.9, n.3, set./dez. 2016. 


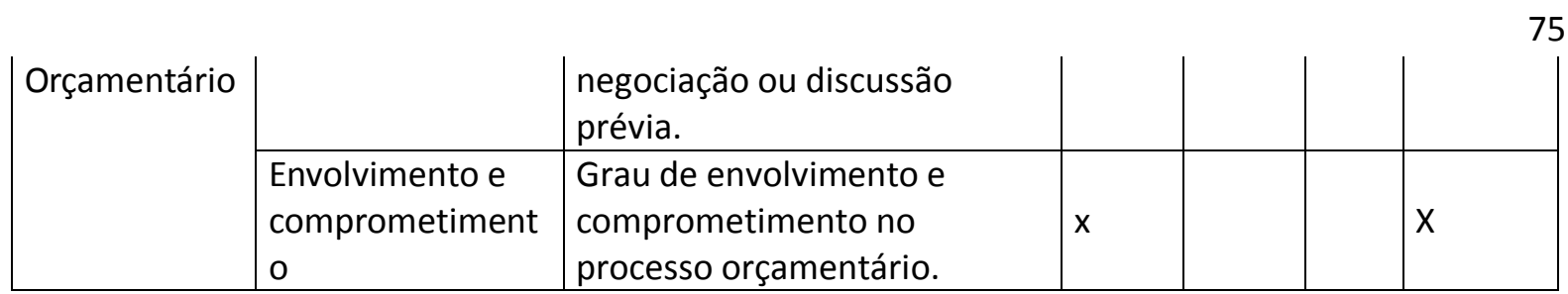

Fonte: Elaborado pelos autores (2016).

Foi verificado que o orçamento é desenvolvido de cima para baixo, ou seja, quotas ou quotas partes são enviadas pelo MEC e Ministério da Saúde para o atendimento das demandas, conforme um teto disponibilizado pelo próprio MEC. Não há liberdade orçamentária. As estimativas são desenvolvidas de acordo com este teto, e não conforme as demandas reais. Essas características, somadas à questão de pouca capacitação dos profissionais na área financeira, contribuem para a baixa participação dos servidores no processo orçamentário como um todo. Estes fatores convergem com o estudo de Caliman (2014).

Quadro 7 - Categoria Comunicação

\begin{tabular}{|c|c|c|c|c|c|c|}
\hline \multirow{3}{*}{ Categoria } & \multirow{3}{*}{ Fatores } & \multirow{3}{*}{ Descrição } & \multicolumn{4}{|c|}{$\begin{array}{l}\text { Impacto sobre a } \\
\text { Institucionalização }\end{array}$} \\
\hline & & & \multicolumn{2}{|c|}{ Como é } & \multicolumn{2}{|c|}{$\begin{array}{l}\text { Como deveria } \\
\text { ser }\end{array}$} \\
\hline & & & Inibe & Estimula & Inibe & Estimula \\
\hline \multirow{4}{*}{ Comunicação } & $\begin{array}{l}\text { Comunicação } \\
\text { top-down }\end{array}$ & $\begin{array}{l}\text { Clareza na comunicação de } \\
\text { cima para baixo. }\end{array}$ & $x$ & & & $x$ \\
\hline & \begin{tabular}{|l|} 
Clareza dos \\
objetivos
\end{tabular} & $\begin{array}{l}\text { Clareza na comunicação dos } \\
\text { objetivos de curto prazo. }\end{array}$ & $x$ & & & $x$ \\
\hline & \begin{tabular}{|l|} 
Comunicação \\
inter setorial
\end{tabular} & Integração e cooperação. & $x$ & & & $x$ \\
\hline & $\begin{array}{l}\text { Comunicação } \\
\text { das metas e } \\
\text { diretrizes }\end{array}$ & $\begin{array}{l}\text { Comunicação eficaz das metas } \\
\text { e diretrizes estabelecidas. }\end{array}$ & $x$ & & & $x$ \\
\hline
\end{tabular}

Fonte: Elaborado pelos autores (2016).

A pluralidade de profissionais, uma estrutura ainda não preparada, e uma subutilização dos sistemas de informação contribuem para uma péssima comunicação gerencial. A comunicação gerencial não é visível entre os setores, ou seja, sabe-se que os gastos estão inseridos no orçamento; no entanto, não há uma forma de comunicação entre os setores para fornecer a informação. Existem setores que desconhecem que possuem uma fatia do orçamento global. A comunicação intersetorial não é satisfatória, corroborando com o estudo de Yen (2004), pois não há comunicação de metas pré-estabelecidas e nem se sabe Revista Eletrônica de Estratégia \& Negócios, Florianópolis, v.9, n.3, set./dez. 2016. 
como as metas são estabelecidas. As informações são passadas da alta administração para os demais gestores sem a devida participação. Apenas são desenvolvidas algumas reuniões para a comunicação de algumas ações. É o fazer de conta que estão participando do processo orçamentário.

Quadro 8 - Categoria Reserva Orçamentária

\begin{tabular}{|c|c|c|c|c|c|c|}
\hline \multirow{3}{*}{ Categoria } & \multirow{3}{*}{ Fator } & \multirow{3}{*}{ Descrição } & \multicolumn{4}{|c|}{\begin{tabular}{|l|} 
Impacto sobre a \\
Institucionalização
\end{tabular}} \\
\hline & & & \multicolumn{2}{|c|}{ Como é } & \multicolumn{2}{|c|}{ Como deveria ser } \\
\hline & & & Inibe & Estimula & Inibe & Estimula \\
\hline $\begin{array}{l}\text { Constituição de } \\
\text { reservas } \\
\text { orçamentárias }\end{array}$ & Insegurança & $\begin{array}{l}\text { Incertezas quanto ao futuro } \\
\text { e aos procedimentos de } \\
\text { gestão adotados } \\
\text { conjuntamente com o } \\
\text { orçamento. }\end{array}$ & $\mathrm{x}$ & & $X$ & \\
\hline $\begin{array}{l}\text { Constituição de } \\
\text { reservas } \\
\text { orçamentárias }\end{array}$ & $\begin{array}{l}\text { Reservas } \\
\text { orçamentária } \\
\mathrm{s}\end{array}$ & $\begin{array}{l}\text { Constituição de reservas } \\
\text { orçamentárias para } \\
\text { manobras de gestão. }\end{array}$ & $\mathrm{x}$ & & $x$ & \\
\hline
\end{tabular}

Fonte: Elaborado pelos autores (2016).

Foi constatado que as reservas orçamentárias são constituídas para que sejam aplicadas em alguma demanda futura, proveniente de fatos não esperados. No entanto, observou-se que são utilizadas para manobras da alta administração, devido ao relacionamento político entre gestores e alta administração. Por ser uma entidade pública, caracterizada por cargos de indicação, mesmo com a inserção da Empresa específica de gestão de hospitais, tal fato não eliminou o vício político. Esta característica converge com os estudos de Caliman (2014) e Junqueira et al. (2015). Há uma coalização política e os demais gestores são obrigados a seguir o direcionamento da alta gestão, ocasionando incertezas na área administrativa e gerencial.

Quadro 9 - Categoria Dados do Passado

\begin{tabular}{|c|c|c|c|c|c|c|}
\hline \multirow{3}{*}{ Categoria } & \multirow{3}{*}{ Fatores } & \multirow{3}{*}{ Descrição } & \multicolumn{4}{|c|}{$\begin{array}{l}\text { Impacto sobre a } \\
\text { Institucionalização }\end{array}$} \\
\hline & & & \multicolumn{2}{|c|}{ Como é } & \multicolumn{2}{|c|}{$\begin{array}{l}\text { Como deveria } \\
\text { ser }\end{array}$} \\
\hline & & & Inibe & $\begin{array}{l}\text { Estimul } \\
\text { a }\end{array}$ & Inibe & $\begin{array}{l}\text { Estimul } \\
\text { a }\end{array}$ \\
\hline $\begin{array}{l}\text { Dados do } \\
\text { Passado }\end{array}$ & $\begin{array}{l}\text { Percepção de } \\
\text { oportunidades }\end{array}$ & $\begin{array}{l}\text { Ausência de percepção de } \\
\text { oportunidades, pois o } \\
\text { orçamento foca excessivamente }\end{array}$ & $X$ & & $x$ & \\
\hline
\end{tabular}

Revista Eletrônica de Estratégia \& Negócios, Florianópolis, v.9, n.3, set./dez. 2016. 


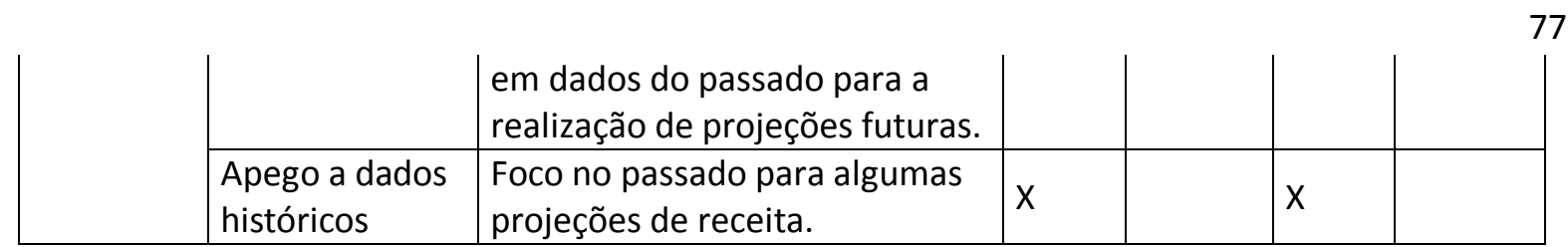

Fonte: Elaborado pelos autores (2016).

Foi verificado que boa parte das estimativas para o desenvolvimento do orçamento do hospital é embasada sobre estimativas históricas anteriores, ou seja, são desenvolvidas utilizando dados do passado, aplicando algum tipo de atualização. Este procedimento acaba por viciar o orçamento a caminhar apenas por uma direção, geralmente política e não gerencial. Esta característica corrobora com o estudo de Frezatti (2011), pois nela há influências sociológicas e psicológicas para a utilização de estimativas anteriores na orçamentação. O fator sociológico está relacionado ao fator de resistência à mudança (HANSEN; OTLEY; VAN DER STEDE, 2003; LIVOVSCHI, 2013), enquanto o fator psicológico está relacionado a um direcionador para a tomada de decisão (BAZERMAN, 2004; LIVOVSCHI, 2013).

Quadro 10 - Categoria Cultura Orçamentária

\begin{tabular}{|c|c|c|c|c|c|c|}
\hline \multirow{3}{*}{ Categoria } & \multirow{3}{*}{ Fatores } & \multirow{3}{*}{ Descrição } & \multicolumn{4}{|c|}{\begin{tabular}{|l|} 
Impacto sobre a \\
Institucionalização
\end{tabular}} \\
\hline & & & \multicolumn{2}{|c|}{ Como é } & \multicolumn{2}{|c|}{$\begin{array}{l}\text { Como deveria } \\
\text { ser }\end{array}$} \\
\hline & & & Inibe & Estimula & Inibe & Estimula \\
\hline \multirow{4}{*}{$\begin{array}{l}\text { Cultura de } \\
\text { planejamento }\end{array}$} & \begin{tabular}{|l|} 
Cultura do \\
planejamento \\
orçamentário \\
\end{tabular} & $\begin{array}{l}\text { Conjunto de crenças e } \\
\text { valores. }\end{array}$ & & $x$ & & $x$ \\
\hline & $\begin{array}{l}\text { Cultura de } \\
\text { rigidez }\end{array}$ & $\begin{array}{l}\text { Dificuldade em lidar com } \\
\text { mudanças ambientais e } \\
\text { ajustar o orçamento. }\end{array}$ & $x$ & & $x$ & \\
\hline & Impessoalidade & $\begin{array}{l}\text { Cultura política para a } \\
\text { solução de questões } \\
\text { relacionadas ao processo } \\
\text { orçamentário. }\end{array}$ & $x$ & & $x$ & \\
\hline & $\begin{array}{l}\text { Cultura do } \\
\text { controle }\end{array}$ & $\begin{array}{l}\text { Cultura do controle das } \\
\text { metas. }\end{array}$ & $x$ & & & $x$ \\
\hline
\end{tabular}

Fonte: Elaborado pelos autores (2016).

Foi constatado que os gestores entendem que os gastos dependem de serem inseridos no orçamento, mas não compreendem a função do mesmo quanto a sua função gerencial. Assim, não possuem uma cultura de planejamento e de controle, pois não compreendem a função que o orçamento pode exercer na sua execução, convergindo com o 
estudo de Reis, et al. (2014). O orçamento é como se fosse um sistema que consta o que pode ou não gastar, apenas. Se estiver escrito pode aplicar; se não estiver, procuram, através da aproximação política, conseguir atender as demandas setoriais. A cultura política é muito aparente na organização. Esta característica também corrobora com o estudo de Junqueira et al. (2014).

Quadro 11 - Categoria realidade das Metas Orçamentárias

\begin{tabular}{|c|c|c|c|c|c|c|}
\hline \multirow{3}{*}{ Categoria } & \multirow{3}{*}{ Fatores } & \multirow{3}{*}{ Descrição } & \multicolumn{4}{|c|}{\begin{tabular}{|l} 
Impacto sobre \\
Institucionalização
\end{tabular}} \\
\hline & & & \multicolumn{2}{|c|}{ Como é } & \multicolumn{2}{|c|}{ Como deveria ser } \\
\hline & & & Inibe & $\begin{array}{l}\text { Estim } \\
\text { ula }\end{array}$ & Inibe & Estimula \\
\hline $\begin{array}{lr}\text { Grau } & \text { de } \\
\text { realidade } & \text { das } \\
\text { metas } & \end{array}$ & $\begin{array}{l}\text { Metas percebidas } \\
\text { como } \\
\text { inconsistentes }\end{array}$ & $\begin{array}{llr}\text { A despesa } & \text { fixada } & \text { não } \\
\text { condiz } & \text { com } & \text { a } \\
\text { realidade. } & & \end{array}$ & $x$ & & $x$ & \\
\hline
\end{tabular}

Fonte: Elaborado pelos autores (2016).

Foi detectado que as demandas estabelecidas no orçamento não refletem a real necessidade da entidade. Como a maior parte do orçamento é fixada pelo MEC e Ministério da Saúde, o Hospital é obrigado a trabalhar com a parcela que é direcionada. Os resultados são a superlotação, falta de equipamentos, falta de remédios, entre outros. Foi verificado que há problemas quanto à gestão, mas, neste momento, a problemática maior fica por conta da escassez de recursos, pois a demanda é sempre crescente e o aumento dos recursos não acompanha este crescimento. Estas características corroboram com o estudo de Caliman (2014). O Hospital é referência em algumas áreas; sendo assim, atende os pacientes do sul da Bahia, leste de Minas Gerais, toda a população do Espírito Santo e até mesmo do norte do Rio de Janeiro.

\section{CONSIDERAÇÕES FINAIS}

O objetivo da pesquisa é investigar os fatores que inibem a institucionalização do orçamento como ferramenta de controle gerencial em um hospital universitário em VitóriaES. Utilizaram-se, como referencial teórico, a literatura de orçamento, Teoria Institucional e Teoria da Complexidade. A análise ocorreu através de estudo de caso e foram utilizadas, como fonte de captação de dados, a entrevista, observação não participante e análises documentais. 
O estudo permitiu compreender as dificuldades dos gestores em utilizar o orçamento como uma ferramenta de gestão e controle gerencial do hospital, devido ao relacionamento político e práticas de gestão, como a criação de reservas orçamentárias e utilização de estimativas históricas.

Na categoria complexidade organizacional, observou-se a imprevisibilidade e relações políticas em sua estrutura, e indícios de relações de poder intrínsecos ao processo orçamentário.

Quanto à categoria estrutura do processo orçamentário, observou-se que deficiências da estrutura contribuem para a inibição da utilização do orçamento, devido à falta de treinamento dos profissionais e à contratação de gestores por indicação política que, muitas vezes, não possuem capacidade técnica adequada para administrar e operacionalizar o orçamento, pois foi verificado que os gestores não obtinham conhecimento sobre o que é orçamento. Possui estruturas arcaicas de organograma, sem indicadores de desempenho (não desenvolvem indicadores internos que possam auxiliar a tomada de decisão) e dificuldade de enxergar o cenário externo (não desenvolvem indicadores externos ao auxílio à gestão).

Observou-se, na categoria sistema de informação, que a instituição possui um sistema de administração financeira que atende a demanda dos profissionais de contabilidade e finanças, mas não possui profissionais capacitados para extrair relatórios gerenciais a fim de auxiliar na gestão do hospital, havendo uma subutilização dos sistemas de informação.

$\mathrm{Na}$ categoria participação no processo orçamentário, verificou-se que não há participação dos gestores neste processo.

Foi observado, na categoria comunicação, que a interlocução é pouco eficaz, pouco clara e quase não existe. A comunicação gerencial também é quase inexistente entre os gestores.

Quanto à categoria constituição de reservas orçamentárias, verificou-se elas sofrem alterações de acordo com as manobras políticas da alta administração, mas tudo dentro da legalidade.

Revista Eletrônica de Estratégia \& Negócios, Florianópolis, v.9, n.3, set./dez. 2016. 
Na categoria dados do passado, observou-se que o hospital ainda segue a prática de orçamento baseado em estimativas históricas anteriores, utilizando projeções passadas com algumas atualizações.

A respeito da cultura de planejamento, constatou-se que os gestores desconhecem as funções do orçamento para o auxílio à gestão. A entidade não possui metas préestabelecidas e seguem orientações da alta administração.

Verificou-se, na categoria grau de realidade das metas, que o hospital recebe um teto financeiro dos Ministérios da Educação e da Saúde, vinculado as ações traçadas por cada Ministério, engessando o orçamento, atendendo somente o que é estipulado e não a demanda real.

Foi constatado que os gestores possuem dificuldades de assimilar mudanças internas e externas, não possuem autonomia e não há treinamentos específicos. Foi verificada uma pluralidade de profissionais com uma relação política significativa, e que impacta o processo orçamentário. As estruturas são deficientes, o processo corre fora de padrões, não possuem indicadores de desempenho fidedignos, o acesso ao sistema de informação é restrito aos profissionais da área de contabilidade, a comunicação gerencial é deficitária, são utilizadas estimativas históricas para o desenvolvimento do orçamento, o orçamento é engessado e Top down, e não condiz com a realidade da instituição.

Desta forma, observando as constatações apresentadas, o orçamento ainda não foi institucionalizado como ferramenta gerencial no hospital universitário. Funciona apenas como instrumento balizador dos gastos do hospital, convergindo, assim, com o estudo de Caliman (2014). No plano teórico, o orçamento foi institucionalizado através de um isomorfismo coercitivo, ou seja, para atender normas e exigências legais de órgãos de controle do governo federal.

Foram verificados 27 fatores inibidores, tais como: culturas de controle e rigidez, impessoalidade e reservas orçamentárias; e que o orçamento no hospital ainda não foi institucionalizado como ferramenta de controle gerencial. Foi constatado que o orçamento funciona como um critério cerimonial de valor, ou seja, traz equilíbrio e legitima a gestão 
frente à sociedade e à comunidade acadêmica em geral, assim como aos órgãos de controle externo, convergindo com os estudos de Caliman (2014) e Junqueira et al. (2015).

O hospital em estudo é referência em algumas áreas específicas, atendendo a pacientes de todo o Estado do Espírito Santo e de Estados vizinhos, como Bahia, Minas Gerais e Rio de Janeiro. Estes Estados aumentam a demanda sem a contrapartida de aporte financeiro, contribuindo para o aumento dos gastos e da sobrecarga de atendimentos.

Sem um controle eficiente com o orçamento, o hospital vai sendo super utilizado, superlotado, caracterizado pela falta de equipamentos, remédios, entre outros. Os gestores ainda necessitam compreender as especificidades de um hospital-escola, a importância da ferramenta, sua eficácia frente à tomada de decisão, e a sociedade deve entender que a entidade é um hospital-escola, ou seja, os serviços hospitalares são prestados no sentido de formar profissionais capacitados.

O estudo foi importante para academia, pois contribuiu para a evolução do modelo de Frezatti et al (2011), com o advento de uma nova categoria de análise: Complexidade Organizacional, que apresentou quatro fatores inibidores, dando continuidade à evolução do modelo, conforme estudos de Caliman (2014).

Como sugestões de pesquisas futuras, poderia ser investigado, de forma mais específica, o impacto das relações políticas, assim como o resultado de suas coalizões para o processo orçamentário em si, sob a perspectiva da Teoria Contingencial. Como limitação, por se tratar de um estudo de caso único, as conclusões não podem ser generalizadas a outras entidades hospitalares. Seria interessante um estudo mais abrangente, em mais hospitaisescolas federais no Brasil, para que as conclusões possam ser ainda mais significativas em relação ao todo.

\section{REFERÊNCIAS}

AGOSTINHO, M. C. E. Administração complexa: Revendo as bases cientificas da administração. Revista de Administração de Empresas - RAE - Eletrônica, v. 2, n. 1, 2003.

ALDRIDGE, J. V. RILEY, G. L. Governing Academic Organizations. Berkeley: IcCutchan Publishing Company, 1977. 
ALMEIDA, L. B. MACHADO, E.A. RAIFUR, L.; NOGUEIRA, D.R. A Utilização do Orçamento como Ferramenta de Apoio à Formulação de Estratégia, de Controle e de interatividade: Um Estudo Exploratório nas Cooperativas Agropecuárias da Região Sul do Brasil. Revista Contabilidade Vista \& Revista, v. 20, n. 3, 2009.

ANSOFF, H.I. A nova estratégia empresarial. São Paulo: Atlas, 1991.

ARNABOLDI, M. LAPSLEY, I. STECCOLINI, I. Performance Management in the Public Sector: the ultimate challenge. Financial Accountability \& Management, 31(1), 245-261, 2015.

BARDIN, L. Análise de Conteúdo. 1a ed. Lisboa, Portugal: Edições 70, 1977.

BAZERMAN, M.H. Processo Decisório: para cursos de Administração, Economia e MBAs. Rio de Janeiro: Elsevier Editora, 2004.

BRAGA, R. Fundamentos e técnicas de administração financeira. São Paulo: Atlas, 1995.

BRYER, A. R. Participation in budgeting: A critical anthropological approach. Accounting, Organizations and Society, 39, p. 511-530, 2014.

BUCKLEY, P. J. MICHIE, J. Firms organizations and contracts. New York: Oxford University Press, 1996.

BURNS, J. SCAPENS, R. W. Conceptualizing management accounting change: an institutional framework. Management Accounting Research. Rio de Janeiro: Elsevier. v. 11, p. 3-25, 2000.

CALIMAN, D. R. Fatores que inibem a institucionalização do orçamento como ferramenta de controle gerencial de uma IFES. Dissertação de Mestrado, PPGADM, Universidade Federal do espírito Santo, Vitória/ES, 2014.

CARNEIRO. M,; MATIAS, A. B. Orçamento Empresarial: teoria, prática e novas técnicas. 1.ed. São Paulo: Atlas, 2011.

CASTANHEIRA, D. F. R.; LUPORINI, C.E.; SOUSA, A. F.;ROJO, C.A. O uso do orçamento empresarial como ferramenta de apoio á tomada de decisão e ao controle gerencial: Um estudo comparado em indústrias farmacêuticas de médio porte. Revista de Finanças Aplicadas, pp. 1-20, 2013.

CHEN, Q. Cooperation in the budgeting process. Journal of Accounting Research, v. 41, n. 5, p.775-796, December, 2003.

CHONG, V. K. CHONG, K. M. Budget goal commitment and informational effects of budget participation on performance: a structural equation modeling approach. Behavioral Research in Accounting, v.14, p.65-86, 2002.

COVALESKI, M. A.; EVANS III, J.H.; LUFT, J.L.;SHIELDS, M.D. Budgeting research: three theoretical perspectives and criteria for selective integration. Journal of Management Accounting Research, v.15, 1, p. 3-49, jul./ set., 2003. 
DAVILA, A. WOUTERS, M. Managing budget emphasis through the explicit design of conditional budgetary slack. Accouting, Organizations and Society, v.30, n.7-8, p.587-608, out./nov., 2005.

DIMAGGIO, P. J. POWELL, W. W. The iron cage revisited: Institutional isomorphism and collective retionality in organizational fields. American Sociological Review, v. 48, 2, apr., p. $147-160,1983$.

DUNK, A. NOURI, H. Antecedents of budgetary slack: a literature review and synthesis. Journal of Accounting Literature, vol.17, p.72-96, 1998.

ESTRADA, A. A. Os fundamentos da teoria da complexidade em Edgar Morin. Akropolis Revista de ciências humanas da UNIPAR, p. 85-90, abr./jun. 2009.

ETHERINGTON, L. TJOSVOLD, D. Managing budget conflicts: contribution of goal interdependence and interaction. Canadian Journal of Administrative sciences, v.15, n.2, p.142-151, 1998.

ETZIONI, A. Modern Organizations. New Jersey: Prentice-Hal, 1964.

FREZATTI, F. Orçamento Empresarial: planejamento e controle gerencial. 4 ed. São Paulo: Atlas, 2007.

FREZATTI, F Orçamento empresarial: planejamento e controle gerencial. 5 ed. São Paulo: Atlas, 2009.

FREZATTI, F.; GUERREIRO, R.; AGUIAR, A.B.; GOUVEA, M.A. Análise do relacionamento entre a contabilidade gerencial e o processo de planejamento das Organizações Brasileiras. Revista de Administração Contemporânea - RAC. P. 33-54, 2005.

FREZATTI, F.; RELVAS, T.R.S. JUNQUEIRA, E.; NASCIMENTO, A.R.; OYADOMARI, J.C. Críticas ao Orçamento: Problemas com o Artefato ou a Não Utilização de uma Abordagem Abrangente de Análise? ASAA - Advances in Scientific and Applied Accounting, v.3, n.2, 2010.

FREZATTI, F.; NASCIMENTO, A.R.; JUNQUEIRA, E.; RELVAS,T.R.S. Processo orçamentário: uma aplicação da análise substantiva com utilização da Grounded Theory. Revista Organizações e Sociedade - O\&S, Salvador, v.18, n.58, p.445-446, jul./set., 2011.

GARRISON, R.; NOREEN, E. Managerial Accounting. McGraw-Hill, 2000.

GERSHENSON, C. HEYLIGHEN, F. How can we think complex? In: Managing organizational complexity: philosophy, theory and application. Editor: RICHARDSON, Kurt. Greenwich: IAP, 2005.

GIL, A. C. Métodos e Técnicas de Pesquisa Social. 6 ed. São Paulo: Atlas, 2009. 
GUERREIRO, R.; FREZATTI, F.; LOPES, A.B.; PEREIRA, C.A. O entendimento da contabilidade gerencial sob a ótica da teoria institucional. Revista Organizações e Sociedade - O\&S, Salvador, v. 12, n. 35, out. / dez., 2005.

GUERREIRO, R. PEREIRA, C. A. REZENDE, A. J. AGUIAR, A. B. Fatores Determinantes do Processo de Institucionalização de uma Mudança na Programação Orçamentária: uma pesquisa ação em uma organização brasileira. Revista de Contabilidade do Mestrado em Ciências Contábeis da UERJ, v.10, n.1, p. 59 - 76, 2005.

HANSEN, S. C. VAN DER STEDE, W. A. Multiple facets of budgeting: an exploratory analysis. Management Accounting Research, v.15, n.4, p. 415 - 439, dez. 2004.

HANSEN, S.C.; OTLEY, D. T.; VAN DER STEDE, W. A. Practice development

in budgeting: an overview and research perspective, Journal of Management

Accounting Research, v. 15, n.1, p. 95-116, 2003.

HEINZMANN, L. M. LAVARDA, C. E. F. Cultura organizacional e o processo de planejamento e controle orçamentário. Revista de Contabilidade e Organizações - RCO, Ribeirão Preto: SP, v. 5 , n. 13, p. 19-19, set./dez., 2011.

HOLLAND, J. H. Hidden Order: How Adaptation Builds Complexity. Oxford: Helix Books, 1996.

HORNGREN, C. T. SUNDEM, G. L. STRATTON, W. O. Contabilidade gerencial. 12 ed. São Paulo: Prentice Hall, 2004.

JUNQUEIRA, E. R. M.; CALIMAN, D.R.; PASCUCI, L.M.; GONZAGA, R.P.; FREZATTI, F. Academia Pratica o Que Ensina? Análise da Institucionalização do Processo Orçamentário em Uma Ifes. XXXIX Encontro da ANPAD, Belo Horizonte, 2015.

LINO, K. M. S. GONÇALVES, M. F, FEITOSA, S. L. Administração hospitalar por competência: O administrador como gestor hospitalar. Trabalho de Conclusão de Curso (Bacharelado em Administração) - Escola Superior da Amazônia. Belém, PA, 2008.

LISSACK, M. R. LETICHE, H. Complexity, Emergence, Resilience, and Coherence: gaining perspective on organizations and their study. Emergence, n. 4, v. 3, p. 72-94, 2002.

LIVOVSCHI, F. R. Fatores socioculturais facilitadores do processo orçamentário eficaz nas organizações. Dissertação de mestrado (Mestrado em Desenvolvimento Profissional e Gerencial) - Pontifícia Universidade Católica de São Paulo. São Paulo, 2013.

LUFT, J.; SHIELDS, M. Maping management accounting graphics and guidelines. Accouting organization and society, v.28, p.169-249, 2003.

MACHADO-DA-SILVA, C. L. FONSECA, V. S. da. CRUBELLATE, J. M. Estrutura, Agência e Interpretação: elementos para uma abordagem recursiva do processo de institucionalização. Revista de Administração Contemporânea - RAC, v. 14, p. 77 - 107, 2010. 
MEYER JUNIOR, V. A escola como organização complexa. In: EYING, A. GHISI, M.L. Políticas e Gestão da Educação Superior. Curitiba: Champagnat, 2007.

MEYER JUNIOR, V. PASCUCCI, L. Estratégia em Contextos Complexos e Pluralísticos. Revista de Administração Contemporânea - RAC, v. 17, n. 5, p. 536 - 555, 2013.

MEYER, J. W. ROWAN, B. Instituionalized organizations: formal structure as myth and ceremony. In: American Journal of Sociology. v.83, n. 2, p. 340-363, 1977.

MINTZBERG, H. Tracking strategies: toward a general theory of strategy formation. New York: Oxford University Press, 2007.

MÓL, A. L. R. ARAÚJO FILHO, G. M. Administração financeira e orçamentária. Brasília: Sistema MEC/UAB, 2008.

MORIN, E. Ciência com consciência. Rio de Janeiro: Bertrand Brasil, 8 ed., 2005.

NORTH, D. Towards a theory of institutional change. Quaterly Review of Econimics and Business. [S.1], inverno, 1991.

OYADOMARI, J. C.; MENDONÇA NETO, O.R.; CARDOSO, R.L.; LIMA, M.P. Fatores que influenciam a adoção de artefatos de controle gerencial nas empresas brasileiras: um estudo exploratório sob ótica da teoria institucional. Revista de Contabilidade e Organizações FEARP/USP, v. 2, n. 2, p. $55-70$, jan./abr. 2008.

PADOVEZE, C. L. Contabilidade Gerencial: um enfoque em sistema de informação contábil. 7 ed. - São Paulo : Atlas, 2010.

PADOVEZE, C. L. TARANTO, F. C. Orçamento empresarial: novos conceitos e técnicas. São Paulo: Pearson Education do Brasil, 2009.

PASCUCCI, L. MEYER JUNIOR, V. Formação de estratégias em sistemas complexos: Estudo comparativo de organizações hospitalares sob a perspectiva pratica. XXXV Encontro da ANPAD, 4 a 7 de set., Rio de Janeiro, RJ, 2011.

PASSOLONGO, C. ICHIKAWA, E. Y. REIS, L. G. dos. Contribuição da teoria institucional para os estudos organizacionais: o caso da universidade estadual de londrina. Revista Negócios, Blumenau, v. 9, n. 1, p. 19-26, 2004.

PATTIO, M. L. P. O impacto do sistema ABC no controle organizacional da Casa de Saúde Santa Maria. Dissertação (Mestrado em Engenharia de Produção) - Universidade Federal de Santa Catarina, Santa Catarina, 2001.

PICCHIAI, D. Mudanças em Instituições Hospitalares: Análise do Processo e Estudo da Ação do Administrador Hospitalar. Relatório de Pesquisa apresentado ao NPP - Núcleo de Pesquisas e Publicações - EAESP-FGV. São Paulo, 1998.

REIS, C.Z.T. OLIVEIRA, A. R. SILVEIRA, S. F. R. CUNHA, N. R. S. Variáveis discriminantes do Nível de Institucionalização do Modelo Orçamentário nas Universidades Federais. Revista de Ciências da Administração, v.16, n. 39, p.83-100, ago. 2014.

Revista Eletrônica de Estratégia \& Negócios, Florianópolis, v.9, n.3, set./dez. 2016. 
FATORES INIBIDORES DA INSTITUCIONALIZAÇÃO EM UM HOSPITAL UNIVERSITÁRIO

Sandra Mara de Castro - Luana Brito Frassi - Adna Matias Caetano - Douglas Roriz Caliman

RICHARDSON, R. J. Pesquisa Social: Métodos e Técnicas. 3 ed. São Paulo: Atlas, 1999.

SANVICENTE, A. Z; SANTOS, C. C. Orçamento na administração de empresas: planejamento e controle. 2 ed. São Paulo: Atlas, 1983.

SARKIS, C. D. Características do processo orçamentário nas Cooperativas de Crédito do Estado de Minas Gerais. Dissertação (Mestrado em Ciências Contábeis) - Programa de PósGraduação em Contabilidade e Controladoria da Universidade Federal de Minas Gerais. Minas Gerais, 2013.

SHIELDS, J.; SHIELDS, M. Antecedents of participative budgeting. Accounting, Organizations and Society, v. 23, n. 1, p. 49-76, jan. 1998.

SOUZA, A. A.; BRAGANÇA, C.G.; BRAGA, A.S.; SOARES, L.A.C.F. Análise da avaliação de desempenho por meio do orçamento em um hospital filantrópico: Estudo de Caso. In: XI Congresso Nacional de excelência em gestão. 2015. Rio de Janeiro. Anais... Rio de Janeiro, 2015.

SOUZA, A. A.; GUERRA, M.; LARA, C.O.; GOMIDE, P.L.R.; PEREIRA, C.M.; FREITAS, D.A. Controle de gestão em organizações hospitalares. Revista de Gestão. USP, São Paulo, v.16, n.3, p-15-29, 2009.

SOUZA, A. A.; OLIVEIRA, L.F.; SOUZA, A.D.; XAVIER, D.O.; XAVIER, A.G. Custeio Baseado em Atividades em Hospitais: Modelagem das Atividades do Setor de Engenharia Clínica. In: XIX Congresso Brasileiro de Custos - Bento Gonçalves, RS, Brasil, 12 a 14 de novembro de 2012. Anais... Rio Grande do Sul, 2012a.

SOUZA, A. A.; MOREIRA, D.R.; SILVA, E.A.; PEREIRA, A.C.C. Avaliação de sistemas de informações de hospitais com base na análise fatorial: uma pesquisa survey em hospitais da região metropolitana de belo horizonte. Revista de Gestão em Sistemas de Saúde - RGSS, São Paulo, v. 1, n. 2, p. 04-40, jul./dez. 2012b.

STACEY, R. D. Complexity and creativity in organizations. San Francisco: Berret-Koehler, 1996.

TOLBERT, P. S. ZUCKER, L. G. A institucionalização da Teoria institucional. In: CLEGG, S. R. HARDY, C. NORD, W. R. CALDAS (Org), M. FACHIN, R. FICHER, T. Handbook de estudos organizacionais: modelos e novas questões em estudos organizacionais, v. 1, p. $196-219$. São Paulo: Atlas, 1999.

TOLBERT, P. S. ZUCKER, L. G. A Institucionalização da Teoria Institucional. In: CLEGG, S. R. HARDY, C. NORD, W. R. CALDAS (Org.), M. FACHIN, R. FICHER, T. Handbook de estudos organizacionais: modelos e novas questões em estudos organizacionais, v. 1. São Paulo: Atlas, 2006.

TORRES, J. J. M. Teoria da complexidade: uma nova visão de mundo par a estratégia. I Encontro Brasileiro de Estudos da Complexidade - I EBEC. Curitiba - 11 a 13 de jul., 2005. 
VANDERBECK, E. J. NAGY, C. F. Contabilidade de Custos. 11 ed. São Paulo: Editora Pioneira Thomson Learning, 2001.

WEICK, K. E. Educational Organizations as Loosely Coupled System. Administrative Science Quarterly, v. 1, n. 21, p. 1 - 19, 1976.

WELSC, G. A. Orçamento Empresarial. 4.ed. São Paulo: Atlas, 1983.

YIN, R. K. Case Study Research - design and methods. Sage Publications Inc., USA, 1989.

YUEN, D. C. Y. Goal characteristics, Communication and Reward Systems, and Managerial Propensity to Create Budgetary Slack. Managerial Auditing Journal. Edição Especial, V. 19, N. 4, p. 517-532, 2004.

ZAN, A. Mudanças na contabilidade gerencial de uma organização: Estudo de caso com diagnóstico institucional. São Paulo, SP, 2006. 